\title{
Interpersonal communications in nursing practice - Key to Quality Health care
}

\section{Brinderjeet Kaur*}

Assistant Consultant, Department of Obstetrics and Gynecology, Santokba Durlabhji Memorial Hospital and Research Center, Jaipur, India

Received: 02 February, 2020

Accepted: 17 July, 2020

Published: 18 July, 2020

*Corresponding author: Dr. Brinderjeet Kaur, Assistant Consultant, Department of Obstetrics and Gynecology, Santokba Durlabhji Memorial Hospital and Research

Center, Jaipur, India,

E-mail: drrateeshsareen@hotmail.com;

dr.bjkaur@gmail.com

Keywords: Interpersonal communication; Nursing staff; Nurses

https://www.peertechz.com

\section{Check for updates}

\section{Abstract}

Interpersonal communication is one of the foundations of quality patient care especially for valuable trio in health care- the doctor, the nursing staff and the patient. Effective communication skills in health care setting are a boon as they not only benefit patient but also the health care provider, in respect to job satisfaction and prevention of work stress which affect health. There is strong need of hour that more training, more awareness is created about barriers to effective communication and empower them with strategies to enhance their receptivity towards patient's queries thereby improving nursing interventions in patient care.

\section{Introduction}

Communication helps ion flow of knowledge from person to person and devlop better interpersonal relationships [1]. Communication and interpersonal skills are the most important factors for improving patient satisfaction, compliance and overall health outcome [2]. Interpersonal communication in recent years has played a pivotal role in successful job performance in any organization, health care been no exception. Nursing staff is the backbone of health care in any country. They are entrusted with the responsibility of delivering quality health services to patient and are not only the primary level of contact with patient but also spend maximum time with patients. The manner in which nursing staff communicates and takes care of patients influence the satisfaction level of patients and notably impact the health care outcome [3]. Nursing staff can make patients understand their illness and treatment and being the first level of contact gain confidence of patients making patients feel like second home. This eventually brings mental peace and creates harmonious environment. It therefore brings good health- physical, social and mental well being to patient's i.e. holistic approach to patient care [4].

\section{How communication affects patients and nurses}

Communication failures leading to catastrophe have been well experienced in health care .One such instance been the wrong administration of medication leading to compromised patient safety. The type of nursing care determines the incidence of revisit of patients to the hospital and therefore can serve as a good yardstick of goodwill and satisfaction of any health care institution among general population.

\section{Advantages of effective communication [4-8]}

1. Compliance-Better Compliance with guidelines of accreditation bodies and regional guidelines.

2. Safety-Minimize medication errors enhancing patient safety.

3. Patient's happiness quotient-It improves patient satisfaction, results in recovery, alleviating anxiety, depression and seclusion.

4. Job satisfaction- The positive feedback from patients helps to reduce stress to certain extent, imparting good job satisfaction.

5. Decision making - In times where patient autonomy and patient's right to determine what shall be done to his/ her body, the decision.

\section{Interpersonal communication in nursing}

Nursing staff plays the role of leader in patient care especially at times when the person (patient) is unable to 
take control of his/ her day to day activities due to debilitating disease or infirmity [9]. "Caring is nursing, and nursing is caring" as stated by Kallergis [10]. Watson defined nursing as a Relationship between two human beings in mutual agreement, one of them as 'provider' and the second one as 'receiver' [11]. Casey and Wallis [12], stressed on the importance of developing a mutually agreed relationship and inculcating patient centric nursing skills to bring out the best in terms of patient care. The hallmark of nursing training and practice was patient centric care. This is the most vital interpersonal relationship in health care and it is a therapeutic interaction that ensures that patient needs are always on top priority irrespective of patient's attitude thereby putting the entire onus on nursing [13].

There is no iota of doubt that the nursing staff is the backbone of individualized patient care. They are entrusted with the responsibility of delivering tailored patient specific treatment, providing necessary information to patients attendants and by providing as well as creating an environment that is best conducive for patient [14]. They also have to mediate between doctor and patient and create a communication bridge so that optimum results of treatment are achieved [15]. One can say that care and communication are just the two sides of the same coin they are inseparable and are complimentary to each other [14-16].

Peplau's theory $[17,18]$, is one of the greatest works in the field of nursing relationships and interpersonal communications and it emphasize on reciprocity between nurses and patients.

The theory is based on following assumption:

1) Both nurse and patient can interact,

2) This interaction helps them to evolve and mature.

3) The two fundamental tools in nursing are-communication and interpersonal skills.

4) Nurses must clearly understand themselves in order to promote their patient's growth and to prevent the limitation of patient's choices to those that nurse's value.

The theory involves interactions between nursing, society or environment, health and man. It describes the relationship into five different phases.

\section{Phase 1: Orientation Phase}

The first and foremost formal phase for building therapeutic relationship coordinated by the nurse involving patients in their treatment addressing to their queries and information pertaining to treatment. The manner in which the nurse introduces herself / himself to the patient showing warmth, empathy and care in this introductory phase is the key factor that promotes interpersonal relationship between nurse and patient. It may start by introduction of nurse to the patient and addressing patients by their formal name initially and then can be inquired whether they prefer it or any not.
One of the important ingredient of effective communication is two way communication, allowing patients to speak and listen carefully as it is in this phase that maximum data is collected. The nursing assessment requires accurate data gathered from patients and calls for effective two way communication between nurses and patients. Once the patient has been greeted, their anxiety decreased the patient is primed for participation in relationship. The nurse describes their role to patients and other information relevant to patient. As no two individuals are alike so is their working style, the same holds true for nursing professionals. The information gathered by them may vary and it is imperative not to overlook this part of the relationship as the exterior part of the real work. There is need for nurse to have open mind so that they are able understand patients' problem and the need for the treatment, and respond appropriately. The orientation phase commences with the decision to treat.

\section{Phase 2: Identification Phase}

The patient and nurse work together to clarify problems and set specific goal and in fact this phase is the working one. In this phase, nurses can help patients in exploring their hidden fears and apprehensions as well as identify their personal strengths and resources. In this way they can direct their energy towards helpful actions. These actions have beneficial effect on patient care, recovery and treatment effectiveness.

\section{Phase 3: Exploitation Phase}

The practical work of nurse-patient relationship happens during exploitation, the nurse guides patient in optimum health facility utilization and attainment of mutually decided goals of therapeutic interventions.

\section{Phase 4: Resolution Phase}

This phase culminates in ending a therapeutic relationship [19]. The earlier targets achieved and new targets for treatment and care come up. The relationship was originally established with purpose and deep and meaningful sharing occurred between the nurse and patient. Whether it's a short term or long term interaction both demand an end or resolution. Operating theater nurse may have a short term relationship with patient, where as a nurse in oncology unit may have a longer duration of relationship.

\section{Phase 5: Termination Phase}

The termination phase is marked by ending of professional relationship between the nurse and patient. Although it may be brief interaction only but it gives opportunity to evaluate their mutual achievements and revisit the time. The summary briefing to the patient can help both the parties for perceiving their mutual goals. There could be emotional bonding at the end. This ending of the relationship could bring emotional burst, feeling of loss, sadness but both have to accept it and move ahead. During termination phase, the nurse and patient identify possible unmet goals and some cases may require referral and follow-up care. 
The patients may respond differently at this phase, they might show regression, anxiety, and act strangely superficial to the nurse or even become more dependent. The nurse has to prepare the patient for the termination of therapeutic relationship. The therapeutic nurse-patient relationship between the nurse and patient will end with a completeness and satisfaction that is rewarding for both the nurse and the patient.

\section{Barriers to communication [20,21]}

The barriers to effective communication can be broadly classified as those related t health care professionals, patient centric and environmental. Health care provider ( Nursing ) related barriers include deficiency in language particularly spoken language, excessive use of jargons, frequent interruptions, inexperience, pre occupation with personal matters and prejudice based on decision making. Many times patients are illiterate or poorly educated, superstitious and with pre conceived notions, their religious and cultural beliefs jeopardize the communication process. Environmental factors may also hinder the effective communication process like long stay on admission counter, lengthy discharge procedure and multiple counters for payments and reports collection as well as ergonomically poorly designed infrastructure that further makes communication with patients unsatisfactory.

\section{How to improve}

Communication with patients can greatly be improved by active listening to patients, keeping one self smiling, showing empathy towards patients, choice of soft words, use of appropriate language which patients can understand, greeting patients with enthusiasm , maintaining honesty, anticipating needs of patients, customizing and giving personalized care, creating a conductive environment, ending relationship in a manner where patient's needs are top priority, ensuring safety of patient, helping them in decision making and meeting out challenges supported by evidence based training.

The basic of interpersonal communication building relies on principles that they are inescapable, irreversible, complicated and contextual. Putting in other way round, they never occur in isolation. Nowadays, they are designated as 'soft skills', which in our opinion is misnomer as these are 'hard skills', which need to be learnt and affect your work performance, career and personal life. Communication has different facets .Psychological context of communication covers employee desires, needs, values, personality etc. Relational context refers to interactions with others. Situational context is psychosocial whereas environmental context deals with physical attributes of place of communication like furniture, location, premises, noise, time of day, ambience of work place. The cultural context also affects type of behavior for instance one can be from a culture where making a long direct eye contact may be insolent to a different cultural background where it is considered reliable [22]. It is imperative that designing a training for communication skill learning, the coordinators emphasize on various domains .

\section{Role and responsibility of organizations}

The organization cannot shred away from their responsibility towards the behavior of their staff. They need to develop strategy, align and engage employee's workforce by putting key elements in place including motivation, 'fit for objective' structure, talented leadership and operative people system. The organization should evolve process like communication to all key stakeholders including nurses stating clearly what, why, when and how the goals can be achieved. They should develop process to ensure that leaders who have knowledge and skills to take action, aligning energy and resources towards fulfillment of strategy. Essentially, the organization should also develop fair, transparent process to measure success, maintain respect of nurses, satisfy their needs and defend their rights without manipulation, dominating or abusing them.

\section{Conclusion}

Good communicate on between nurses and a patient is of vital significance as it provides patients with individualized care. Nurses who take the time to understand the unique challenges and concerns of their patients will be better prepared to advocate on their behalf and properly address issues as they arise. The attention given to the patient makes patients more compliant with treatment and imparts feeling of safety, affection and confidence, all of which are important during a patient's treatment and recovery. Therefore, this aspect in healthcare should never be neglected and reinforced with training, learning and practice of soft skills.

\section{References}

1. Brinkert R (2010) A literature review of conflict communication causes, costs, benefits and interventions in nursing. J Nurs Manag 18: 145-156. Link: https://bit.ly/30jjvsr

2. Berengere DN, Lori DB, Orlando $H$, Julia R, Debra R (1997) Improving Interpersonal Communication between Health care providers and clients. Quality Assurance Methodology Refinements Series Quality assurance Project. Link: https://bit.ly/3fxTWua

3. Ennis G, Happell B, Broadbent M, Reis-Searl K (2013) The Importance of Communication for Clinical Leadership in Mental Health Nursing: The Perspective of Nurses Working in Mental Health. Ment Health Nurs 34: 814819. Link: https://bit.ly/2WsChwl

4. Wilkinson S (1991) Factors which influence how nurses communicate with cancer patients. J Adv Nurs 16: 677-688. Link: https://bit.ly/3jbzm55

5. Casey A, Wallis A (2011) Effective communication: Principle of Nursing Practice E. Nursing Standard 25: 35-37. Link: https://bit.ly/32nKRQZ

6. Senn JF (2013) Peplau's theory of interpersonal relations: application in emergency and rural nursing. Nurs Sci Q 26: 31-35. Link: https://bit.ly/396TwZb

7. Groves W (2014) Professional Practice skills for nurses. Nursing Standard 29: 51-59. Link: https://bit.ly/2WuCfUR

8. Tay LH, Hegney D, Ang E (2011) Factors affecting Effective Communication between Registered Nurses and Adult Cancer Patients in an Inpatient Setting: A Systematic Review. Int J Evid Based Healthc 9: 151-164. Link: https://bit.ly/3fDJCRw

9. Carter MA (2009) Trust, power, and vulnerability: a discourse on helping in nursing. Nurs Clin North Am 44: 393-340. Link: https://bit.ly/2DQW16C 
10. Kallergis $\mathrm{G}$ (2000) Guide of information and communication with the patient: Personalization, therapeutic relationship, character, family. Medical Graphics.

11. Treiman K, McCormack L, Olmsted M, Roach N, Reeve BB, et al. (2017) Engaging patient advocates and other stakeholders to design measures of patient-centered communication in cancer care. Patient 10: 93-103. Link: Link: https://bit.ly/3jejWgz

12. Casey A, Wallis A (2011) Effective communication: Principle of Nursing Practice E. Nursing Standard 25: 35-37. Link: https://bit.ly/30lOLHk

13. College of Nurses of Ontario (2006) Therapeutic nurse-client relationship. Link: https://bit.ly/2CGnd7p

14. Crawford P, Peter N, Brian B (1998) Communicating care the language of nursing. Link: https://bit.ly/20A75qW

15. Bello O (2017) Effective communication in nursing practice: a literature review. Link: https://bit.ly/3h5ewT2

16. Andriyanto A (2019) Communication barrier between nurse and patient at the hospital: a systematic review. J Health Policy Manag 4: 105-110. Link: https://bit.ly/2WuDpjb
17. Halligan $P$ (2006) Caring for patients of Islamic denomination: critical care nurses' experiences in Saudi Arabia. J Clin Nurs 15: 1565-1573. Link: https://bit.ly/20xGZVp

18. Hammoudi BM, Ismaile S, Abu Yahya O (2017) Factors associated with medication administration errors and why nurses fail to report them. Scand $J$ Caring Sci 32: 1038-1046. Link: https://bit.ly/30nJWxa

19. Sheldon LK (2013) Establishing a Therapeutic Relationship Communication for Nurses: Talking with Patients (third edition). Jones \& Bartlett Learning. Link: https://bit.ly/3fDZB1Z

20. Fine RL (2010) Keeping the patient at the centre of [8] patient-and family-centred care. J Pain Symptom Manage 40: 621-625. Link: https://bit.ly/3fCDQzx

21. Pereira CR, Calônego MAM, Lemonica, Lino L, de Barros GAM (2017) The P-A-C-I-E-N-T-E Protocol: An instrument for breaking bad news adapted to the Brazilian medical reality. Rev Assoc Med Bras 63: 43-49. Link: https://bit.ly/3eGuTUu

22. Lunenburg FC, Irby BJ (2006) The principal ship: Vision to action. Belmont, CA: Wadsworth/Cengage. Link: https://bit.ly/2ZD66ME

\section{Discover a bigger Impact and Visibility of your article publication with} Peertechz Publications

\section{Highlights}

* Signatory publisher of ORCID

* Signatory Publisher of DORA (San Francisco Declaration on Research Assessment)

* Articles archived in worlds' renowned service providers such as Portico, CNKI, AGRIS, TDNet, Base (Bielefeld University Library), CrossRef, Scilit, J-Gate etc.

* Journals indexed in ICMJE, SHERPA/ROMEO, Google Scholar etc.

- OAI-PMH (Open Archives Initiative Protocol for Metadata Harvesting)

* Dedicated Editorial Board for every journal

* Accurate and rapid peer-review process

* Increased citations of published articles through promotions

* Reduced timeline for article publication

Submit your articles and experience a new surge in publication services (https://www.peertechz.com/submission).

Peertechz journals wishes everlasting success in your every endeavours.

Copyright: (c) 2020 Kaur B. This is an open-access article distributed under the terms of the Creative Commons Attribution License, which permits unrestricted use, distribution, and reproduction in any medium, provided the original author and source are credited 